\title{
Increased hepatitis $C$ virus co-infection and injection drug use in HIV-infected fishermen in Myanmar
}

\author{
Janet Ousley ${ }^{1,3^{*}+}$ D, Robin Nesbitt ${ }^{1 \dagger}$, Nang Thu Thu Kyaw ${ }^{1}$, Elkin Bermudez ${ }^{1}$, Kyi Pyar Soe $^{1}$, Rey Anicete ${ }^{1}$,
} Phyu Ei Mon', Win Le Shwe Sin Ei ${ }^{1}$, Susannah Christofani ${ }^{1}$, Marcelo Fernandez ${ }^{1}$ and Iza Ciglenecki ${ }^{2}$

\begin{abstract}
Background: In Southeast Asia, though fishermen are known to be a key population at high risk of HIV, little is known about their co-infection rates with Hepatitis $\mathrm{C}$ virus $(\mathrm{HCV})$, or how illness and risk behaviors vary by occupation or type of fishermen. In Myanmar, this lack of knowledge is particularly acute, despite the fact that much of the country's border is coastline.

Methods: We conducted a retrospective analysis to assess clinical, demographic, and risk characteristics of HIV-infected, $\geq 15$-year-old males under HIV care from 2004 to 2014. Subgroups of fishermen were categorized according to the location of fishing activities, boat ownership, and length of time at sea. Generalized linear models assessed odds of high risk behaviors, including MSM (men who have sex with men), transactional sex, injection drug use (IDU), and HCV co-infection among international, local subsistence, and national migrant fishermen.

Results: Of 2798 adult males who enrolled in HIV care between 2004 and 2014, 41.9\% ( $n=1172)$ were fishermen. Among these, migrants had the highest odds of engaging in risk behaviors such as sex work (Myanmar national migrants: OR 3.26 95\% Cl: 2.20 to 4.83), and injecting drugs (international migrants: OR 2.93, 95\% Cl: 1.22 to 3.87) when compared to the general male HIV clinic population. 15.9\% of all fishermen reported past or current IDU (23.0\% of international migrants). $22.8 \%$ of all fishermen were also co-infected with $\mathrm{HCV}$, and though predictably injectors had the highest odds (OR 20.1, 95\% Cl: 13.7 to 29.5), even after controlling for other risk factors, fishermen retained higher odds (OR 2.37 95\% Cl: 1.70 to 3.32).

Conclusions: HIV positive fishermen in Myanmar had higher odds of HCV co-infection. They also disproportionally injected drugs and engaged in transactional sex more than other patients. This is especially pronounced among international migrant fishermen. HIV-infected fishermen should be counseled on high risk activities, screened for $\mathrm{HCV}$, and targeted by harm reduction programs.
\end{abstract}

Keywords: Migration, Risk behaviors, Southeast Asia, Epidemiology-HIV/AIDS

\section{Background}

Due to the mobile nature of seafaring, fishing industry communities' close sexual networks, and their relative access to cash and income (and often, thus, the frequency with which they engage in transactional sex),

\footnotetext{
* Correspondence: janetousley1@gmail.com

${ }^{\dagger}$ Janet Ousley and Robin Nesbitt contributed equally to this work.

'MSF-Switzerland, Myanmar Project, \#101 Dhama Zedi Road, Kamayut Tsp, Yangon, Myanmar

${ }^{3}$ Medecins Sans Frontiers, 333 7th Avenue, 2nd Floor, New York, NY 10001, USA

Full list of author information is available at the end of the article
}

fishermen have long been recognized as vulnerable to HIV infection [1-4]. In Southeast Asia, where fisheries employ an estimated 30 million people and supply a quarter of global fish production annually, a prior review found HIV seroprevalence rates among fishing communities to be between 4.6 and 14 times higher than in the general population, ranging from $15.5 \%$ in Thailand $(n=818)$, $16.2 \%$ in Cambodia $(n=465)$, and $12.4 \%$ in Malaysia $(n=398)$ [5-8]. In Myanmar, despite an abundance of coastline and fishing related economic activity, fishermen remain mostly unmonitored by HIV surveillance

(c) The Author(s). 2018 Open Access This article is distributed under the terms of the Creative Commons Attribution 4.0 International License (http://creativecommons.org/licenses/by/4.0/), which permits unrestricted use, distribution, and reproduction in any medium, provided you give appropriate credit to the original author(s) and the source, provide a link to the Creative Commons license, and indicate if changes were made. The Creative Commons Public Domain Dedication waiver (http://creativecommons.org/publicdomain/zero/1.0/) applies to the data made available in this article, unless otherwise stated. 
systems, international organizations, and national AIDS programming [9]. What's more, the very behaviors that leave fishermen susceptible to HIV infection may also expose them to other infections such as hepatitis $C$ virus $(\mathrm{HCV})$, particularly among injection drug users [10]. This study describes the clinical, demographic, and treatment characteristics of HIV-infected fishermen attending an MSF HIV clinic, and compares their risk characteristics with non-fishermen HIV-infected males at the same clinical site. It is the first to look at this patient population in Myanmar.

\section{Methods}

\section{Study design}

A retrospective cohort analysis was conducted using a convenience sample of anonymized medical data for all patients presenting between 2004 and 2014.

\section{Study context}

Medecins Sans Frontiers (MSF) has been operating an HIV clinic in Dawei District, Tanintharyi Division, in southern Myanmar, since 2004. One of the two largest fish producing areas in the country, Tanintharyi generated 650,000 tons of fish during the 2009-2010 seasons, over twice the yield of the next most productive state, according to recent data [11]. The entire Western border of the region is coastline bordering the Andaman sea, and much of the population lives along this coast or along multiple rivers and tributaries, providing ample opportunities for fishing both within Myanmar waters and in the international waters off of Thailand and beyond [12]. MSF is providing HIV testing, treatment and care for high risk groups, including those working in fishing related industries.

All data used in this analysis were gathered as part of routine clinical assessments at the MSF facility and research procedures were in accordance with the Declaration of Helsinki. Analysis fulfilled the exemption criteria set by the Médecins Sans Frontières Ethics Review Board for a posteriori analyses of routinely collected, de-identified clinical data and thus did not require ERB review, nor did it require Myanmar National ERB approval as a review of anonymized programmatic information [13].

\section{Study population}

All adult male ( $\geq 15$ years) HIV positive patients who accessed HIV care at the MSF Dawei clinic from 2004 to 2014 were included. For the purposes of our study, a fisherman was defined as a person who, upon presentation to care, self-reported catching fish as their primary income generating activity (though were not necessarily involved in the resale, transfer, or processing of fish). Occupation was established during an interview at the initial clinic visit, and data were de-identified using an anonymous patient number. Three subgroups of fishermen existed and were categorized according to the location of fishing activities, boat ownership, and length of time at sea: 1) local subsistence fishermen worked on smaller boats, owned by themselves or another Myanmar citizen, and spent shorter lengths of time at sea, sometimes even returning home the same day; 2) Myanmar migrant fishermen were those whose fishing occurred further away from Dawei along Myanmar's coastline and may have spent somewhat longer lengths of time at sea, a few days to a few weeks, also in a vessel owned by a Myanmar citizen; and 3) international migrant fishermen worked on boats owned by a foreigner, often deep-sea vessels traveling in international waters, and often spending months away from home.

\section{Statistical analyses}

Baseline demographic and treatment characteristics were compared between fishermen and non-fishermen patients using means with their standard deviations (SD), or medians with corresponding interquartile ranges (IQR) for continuous variables, and frequencies and proportions for categorical data. Tests for differences between fishermen and the general male cohort were performed using Mann-Whitney $\mathrm{U}$ tests or $\mathrm{t}$-tests for continuous variables and chi squared tests for categorical variables.

Three behavioural risk factors for HIV were investigated in the total male cohort enrolled in HIV care (i.e. those who initiated antiretroviral therapy as well as those who do not): transactional sex with a commercial sex worker (CSW); men who have sex with men (MSM); and intravenous drug use (IDU). Odds ratios for these factors were analyzed using generalized linear models with binomial distribution and robust standard errors. Risk factors for HCV co-infection (expressed as positive $\mathrm{HCV}$ seroprevalence using Oraquick Rapid Antibody Test) were investigated amongst patients who had been tested whilst on ART, using the same statistical procedures; these included clinical and demographic characteristics (age, BMI, CD4 count, marital status, WHO stage) as well as behavioural risk factors for HIV.

\section{Results}

\section{Demographic characteristics}

There were a total of 2798 HIV positive adult males who accessed HIV care at the MSF clinic from July 2004 until December 2014 (Fig. 1). Amongst those enrolled in HIV care, fishing was reported as the most common occupation $(n=1172,41.9 \%)$. Other migrant work (non-fishing; $31.0 \%)$ and manual workers (14.8\%) were also common. Of the fishermen who enrolled in HIV care, 453 (38.6\%) were local subsistence fishermen, 239 (20.4\%) were Myanmar migrants and $480(41.0 \%)$ were international migrant fishermen. There was no difference in mean age 


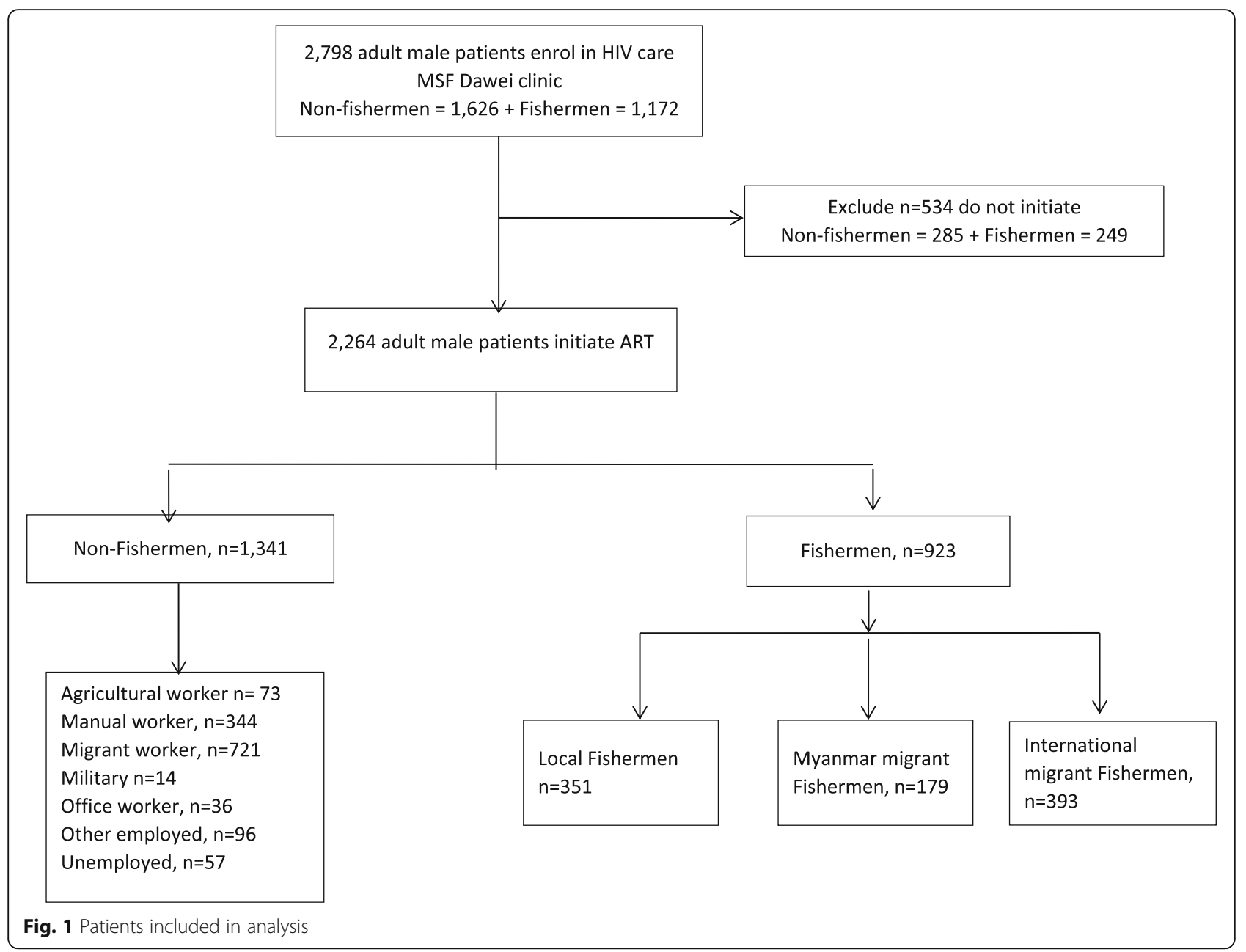

at enrolment in HIV care between fishermen and non-fishermen (36.9 and 37.1 years respectively, $p=0.6$ ), although a higher proportion of fishermen were 30-49 years (Table 1). Fishermen and non-fishermen differed in their marital status, with fewer fisherman married (51.6\% vs $58.6 \%, p=0.003)$.

\section{High risk behaviour}

Male fishermen in care engaged in high-risk activities more than non-fishermen enrolled in HIV care. Fishermen had 2.5 times higher odds of buying sex from a CSW than the general cohort (OR $2.5395 \% \mathrm{CI}: 2.09$ to 3.06), the highest odds among Myanmar migrant fishermen (OR 3.26 95\% CI: 2.20 to 4.83 ), of whom $87 \%$ reported buying sex from a CSW (Table 2). In addition, fishermen had almost $90 \%$ higher odds of current or past IV drug use than non-fishermen (OR 1.89 95\% CI: 1.49 to 2.39). This was driven by the higher prevalence of drug use in international fishermen, who had almost three times the odds of IDU in adjusted models (OR 2.93, 95\% CI: 2.22 to 3.87) and among whom $23 \%$ reported past or current drug use, compared to $13 \%$ of local fishermen and $8 \%$ of both non-fishermen and Myanmar migrant groups. There were lower odds of MSM among fishermen compared to non-fishermen (OR 0.34, 95\% CI: 0.23 to 0.48 ), also in all fishermen subgroups.

Clinical, immunological, and treatment characteristics At presentation, fishermen had a slightly higher median BMI (19.0 IQR 17.4-20.6) than non-fishermen (18.7 IQR $17-20.5, p=0.01$ ), though no statistical difference in CD4 count between the two groups (90 IQR 30-233 vs 84 IQR 39-198, $p=0.18$ Table 1). Slightly more fishermen enrolled later in HIV care than non-fishermen $(78.8 \% \mathrm{WHO}$ stage $3 / 4$, vs $75.4 \%, p=0.038$ ), failed to initiate ART (78.8 vs $82.5 \%, p=0.014)$, and had a longer median time to ART initiation (42 days vs 32 days, $\mathrm{p}=<0.01$ ).

\section{Hepatitis C virus (HCV) CO-INFECTION}

Of the HIV patients on ART, 1648 (72.8\%) were screened for $\mathrm{HCV}$, with equal proportions screened from both occupational groups $(72.1 \%$ fishermen vs $73.3 \%$ non-fishermen, $p=0.51)$. Significantly more fishermen were $\mathrm{HCV}$ seropositive than non-fishermen $(23.2 \%$ vs 
Table 1 Baseline characteristics of male HIV+ adults at enrolment in HIV care at Dawei clinic- n=2798

\begin{tabular}{|c|c|c|c|c|c|c|}
\hline \multirow[t]{2}{*}{ Characteristics } & & \multicolumn{2}{|c|}{ General $(n=1626)$} & \multicolumn{2}{|c|}{ Fishermen $(n=1172)$} & \multirow[t]{2}{*}{$p$-value } \\
\hline & & $n$ & $\%$ & $n$ & $\%$ & \\
\hline \multirow[t]{4}{*}{ Age (years) } & $15-29$ & 355 & 21.7 & 191 & 16.3 & $<0.001$ \\
\hline & $30-49$ & 1141 & 70.3 & 906 & 77.3 & \\
\hline & $50+$ & 130 & 8.0 & 75 & 6.4 & \\
\hline & Mean $(s d)$ & 37.1 & (8.8) & 36.9 & $(7.5)$ & 0.6 \\
\hline \multirow[t]{4}{*}{ Marital status } & Married & 952 & 58.6 & 605 & 51.6 & 0.003 \\
\hline & Single & 427 & 26.3 & 350 & 29.9 & \\
\hline & Divorced & 140 & 8.6 & 127 & 10.8 & \\
\hline & Widow & 107 & 6.6 & 90 & 7.68 & \\
\hline \multirow[t]{4}{*}{ BMI } & $>18.5^{2}$ & 791 & 48.7 & 598 & 51.0 & 0.001 \\
\hline & $<18.5$ & 699 & 43.0 & 435 & 37.1 & \\
\hline & Missing & 136 & 8.4 & 139 & 11.9 & \\
\hline & Median (IQR) & 18.7 & $(17-20.5)$ & 19.0 & $(17.4-20.6)$ & 0.01 \\
\hline \multirow[t]{7}{*}{ CD4 count } & $<50$ & 415 & 25.5 & 292 & 24.9 & 0.025 \\
\hline & 50 & 421 & 25.9 & 305 & 26.0 & \\
\hline & 200 & 173 & 10.6 & 105 & 9.0 & \\
\hline & 350 & 89 & 5.5 & 52 & 4.4 & \\
\hline & 500 & 83 & 5.1 & 41 & 3.5 & \\
\hline & Missing & 445 & 27.4 & 377 & 32.2 & \\
\hline & Median (IQR) & 90 & $(30-233)$ & 84 & (39-198) & 0.18 \\
\hline \multirow[t]{4}{*}{ WHO Stage } & 1 & 165 & 10.2 & 73 & 6.2 & 0.004 \\
\hline & 2 & 235 & 14.5 & 176 & 15.0 & \\
\hline & 3 & 833 & 51.2 & 633 & 54.0 & \\
\hline & 4 & 393 & 24.2 & 290 & 24.7 & \\
\hline \multirow[t]{3}{*}{ Risk factors for HIV acquisition } & IDU & 138 & 8.49 & 186 & 15.9 & $<0.001$ \\
\hline & CSW & 1086 & 66.9 & 980 & 83.7 & $<0.001$ \\
\hline & MSM & 157 & 9.7 & 47 & 4.02 & $<0.001$ \\
\hline Initiate ART & & 1341 & 82.5 & 923 & 78.8 & 0.014 \\
\hline HCV positive ${ }^{3}$ & & 93 & 9.5 & 154 & 23.2 & $<0.001$ \\
\hline
\end{tabular}

${ }^{1}$ Total includes $n=2$ non-fishermen who are $<15$ at enrolment but $>15$ at ART initiation, $p$-values from chi square or Mann-Whitney $\mathrm{U}$ test for BMI and CD4 count and t-test for age; ${ }^{2}$ this category includes 37 patients with $\mathrm{BMI}>24.9$ and 3 patients with $\mathrm{BMI}>30 ;{ }^{3}$ amongst 1648 screened for HCV. ${ }^{*} A R T=$ antiretroviral therapy

Table 2 Crude and adjusted odds ratios for MSM, CSW, IDU in male HIV+ adults at enrolment in HIV care at Dawei clinic (include those who initiate and do not initiate ART)- comparing fishermen and fishermen subtypes to the general non-fishermen cohort

\begin{tabular}{|c|c|c|c|c|c|c|c|c|c|c|c|c|c|c|c|}
\hline & \multicolumn{5}{|c|}{$\operatorname{MSM}(n=2781)$} & \multicolumn{5}{|c|}{$\operatorname{CSW}(n=2793)$} & \multicolumn{5}{|c|}{ IDU $(n=2974)$} \\
\hline & \multirow[b]{2}{*}{$\%$} & \multicolumn{2}{|c|}{ Crude } & \multicolumn{2}{|c|}{ Adjusted } & \multirow[b]{2}{*}{$\%$} & \multicolumn{2}{|c|}{ Crude } & \multicolumn{2}{|c|}{ Adjusted } & \multirow[b]{2}{*}{$\%$} & \multicolumn{2}{|c|}{ Crude } & \multicolumn{2}{|c|}{ Adjusted } \\
\hline & & $\mathrm{OR}$ & $95 \% \mathrm{Cl}$ & OR & $95 \% \mathrm{Cl}$ & & OR & $95 \% \mathrm{Cl}$ & OR & $95 \% \mathrm{Cl}$ & & OR & $95 \% \mathrm{Cl}$ & $\mathrm{OR}$ & $95 \% \mathrm{Cl}$ \\
\hline Non-fishermen & 9.7 & 1 & & 1 & & 66.9 & 1 & & 1 & & 8.5 & 1 & & 1 & \\
\hline Fisherman & 4.0 & 0.39 & $0.28-0.54$ & 0.34 & $0.23-0.48$ & 83.7 & 2.53 & $2.10-3.05$ & 2.53 & $2.09-3.06$ & 15.9 & 2.03 & $1.61-2.57$ & 1.89 & $1.49-2.39$ \\
\hline Non-fishermen & 9.7 & 1 & & 1 & & 66.9 & 1 & & 1 & & 8.5 & 1 & & 1 & \\
\hline Local & 3.5 & 0.34 & $0.20-0.57$ & 0.29 & $0.17-0.50$ & 79.3 & 1.88 & $1.47-2.42$ & 1.91 & $1.48-2.46$ & 12.6 & 1.55 & $1.12-2.15$ & 1.49 & $1.07-2.06$ \\
\hline International & 3.8 & 0.36 & $0.22-0.60$ & 0.31 & $0.18-0.52$ & 86.2 & 3.09 & $2.33-4.09$ & 3.07 & $2.31-4.08$ & 23.0 & 3.21 & $2.44-4.22$ & 2.93 & $2.22-3.87$ \\
\hline Myanmar & 5.5 & 0.54 & $0.30-0.96$ & 0.49 & $0.26-0.91$ & 87.0 & 3.31 & $2.24-4.90$ & 3.26 & $2.20-4.83$ & 8.0 & 0.93 & $0.56-1.53$ & 0.85 & $0.52-1.41$ \\
\hline
\end{tabular}

$\%$ with outcome (MSM, CSW, IDU) Reference group is always general non-fishermen cohort; adjusted models include age at enrolment and marital status 
9.5\%, $p<0.001$ ), with $28.5 \%$ of international fishermen and $21.5 \%$ of local fishermen screening positive for the disease, respectively, corresponding to 2.4 times higher odds of HCV co-infection compared to the general cohort in adjusted models (Table 3). When disaggregated by fisherman subtype, local and international fishermen had 2.6 times higher odds of HCV co-infection. The biggest risk factor for $\mathrm{HCV}$ infection was past or current IV drug use, and $67 \%$ of adult males on ART who reported IDU also screening HCV seropositive. IDU was associated with a 20-fold increased odds of infection (OR 20.1, 95\% CI: 13.7 to 29.5), though even after accounting for IDU in an adjusted model, fishermen retained higher odds of HCV infection (OR 2.37, 95\% CI: 1.70-3.32, Table 3, adjusted model 1).

\section{Discussion}

This analysis establishes the clinical, demographic, and risk characteristics of a cohort of adult HIV patients about which, to date, no information has been published in Myanmar or in Southeast Asia. Occupations that demand mobility or migration are, by definition, less stable. In this case, they may also hold more health risks: Fishermen often have little access to health facilities and sources of health information while at sea, and they may be socially marginalized and endure real physical risks as part of their work. Weekly, seasonal, or long term migration is an expected part of the occupation, and close knit peer networks replacing family and community while far from home can increase the frequency of unsafe activities fishermen engage in [8].

Table 3 HCV co-infection in HIV + males initiated on ART at MSF clinic in Dawei- 2004-2014, $n=1648$

\begin{tabular}{|c|c|c|c|c|c|c|c|c|}
\hline \multirow[t]{2}{*}{ Characteristics } & & \multirow{2}{*}{$\begin{array}{l}\mathrm{HCV}+ \\
\%\end{array}$} & \multicolumn{2}{|c|}{$\begin{array}{l}\text { Crude } \\
n=1648\end{array}$} & \multicolumn{2}{|c|}{$\begin{array}{l}\text { Adjusted model } 1 \\
n=1639\end{array}$} & \multicolumn{2}{|c|}{$\begin{array}{l}\text { Adjusted model } 2 \\
n=1639\end{array}$} \\
\hline & & & $\mathrm{OR}$ & $95 \% \mathrm{Cl}$ & $\mathrm{OR}$ & $95 \% \mathrm{Cl}$ & $\mathrm{OR}$ & $95 \% \mathrm{Cl}$ \\
\hline \multirow[t]{2}{*}{ Occupation } & Non-fisherman & 9.5 & & & 1 & & & \\
\hline & Fisherman & 23.2 & 2.88 & $2.18-3.81$ & 2.37 & $1.70-3.32$ & & \\
\hline \multirow[t]{4}{*}{ Fisherman sub-groups } & Non-fisherman & 9.5 & & & & & & \\
\hline & Local & 21.5 & 2.62 & $1.80-3.81$ & & & 2.66 & $1.75-4.04$ \\
\hline & International & 28.5 & 3.82 & $2.73-5.34$ & & & 2.59 & $1.70-3.96$ \\
\hline & Myanmar & 15.1 & 1.7 & $1.02-2.84$ & & & 1.50 & $0.77-2.91$ \\
\hline \multirow[t]{3}{*}{ Age at initiation } & $15-29 y r s$ & 7.2 & & & 1 & & & \\
\hline & $30-49$ yrs & 17.2 & 2.68 & $1.65-4.38$ & 2.26 & $1.40-3.65$ & 2.25 & $1.39-3.63$ \\
\hline & $50+$ & 8.4 & 1.18 & $0.53-2.63$ & 1.59 & $0.70-3.64$ & 1.59 & $0.69-3.65$ \\
\hline \multirow[t]{4}{*}{ Marital status } & Married & 13.2 & & & & & & \\
\hline & Single & 19.1 & 1.56 & $1.15-2.10$ & 1.23 & $0.84-1.79$ & 1.23 & $0.84-1.79$ \\
\hline & Divorced & 16.1 & 1.26 & $0.78-2.05$ & 0.9 & $0.50-1.64$ & 0.92 & $0.50-1.67$ \\
\hline & Widow & 11.8 & 0.88 & $0.48-1.62$ & 0.9 & $0.41-1.93$ & 0.9 & $0.42-1.93$ \\
\hline \multirow[t]{3}{*}{ BMI at initiation } & $<18.5$ & 12.4 & & & & & & \\
\hline & $>18.5$ & 16.2 & 1.37 & $0.90-2.08$ & 1.21 & $0.71-2.06$ & 1.22 & $0.72-2.09$ \\
\hline & Missing & 15.1 & 1.26 & $0.84-1.88$ & 1.25 & $0.73-2.14$ & 1.23 & $0.72-2.12$ \\
\hline \multirow[t]{6}{*}{ CD4 count at initiation } & $<50$ & 14.7 & & & & & & \\
\hline & 50 & 17.9 & 1.27 & $0.85-1.89$ & 1.49 & $0.88-2.53$ & 1.55 & $0.91-2.64$ \\
\hline & 200 & 7.7 & 1.03 & $0.71-1.49$ & 0.86 & $0.41-1.83$ & 1.26 & $0.74-2.16$ \\
\hline & 350 & 16.9 & 0.49 & $0.26-0.91$ & 2.01 & $0.92-4.37$ & 0.86 & $0.40-1.83$ \\
\hline & 500 & 18.9 & 1.18 & $0.61-2.31$ & 1.29 & $0.40-4.20$ & 2.02 & $0.92-4.44$ \\
\hline & Missing & 15.0 & 1.36 & $0.56-3.26$ & 1.29 & $0.76-2.18$ & 1.35 & $0.42-4.42$ \\
\hline \multirow[t]{2}{*}{ WHO Stage } & $1 / 2$ & 8.9 & 1 & & 1 & & & \\
\hline & $3 / 4$ & 16.1 & 1.98 & $1.26-3.11$ & 1.45 & $0.84-2.50$ & 1.46 & $0.85-2.52$ \\
\hline \multirow[t]{3}{*}{ Risk factors for HIV acquisition ${ }^{a}$} & IDU & 67.0 & 22.81 & $15.99-32.54$ & 20.1 & 13.69-29.52 & 19.73 & $13.45-28.94$ \\
\hline & MSM & 5.7 & 0.32 & $0.16-0.66$ & 0.45 & $0.20-1.01$ & 0.46 & $0.21-1.03$ \\
\hline & CSW & 16.2 & 1.45 & $1.05-2.02$ & 1.00 & $0.67-1.50$ & 1.02 & $0.68-1.53$ \\
\hline
\end{tabular}


Our results confirm that Myanmar fishermen also lead lifestyles suffused with risk, yet remain largely untargeted as a subgroup by social services and health and risk education providers in the country. Over $80 \%$ of fishermen under MSF's care reported engaging in commercial sex (especially common in migrants away from their homes and families), which was particularly troubling since past meta-analyses have found that up to 90\% of fishermen use condoms infrequently with their primary partners [14]. High risk IDU, especially among international fishermen, is also troubling in the world's second largest opium producer (Myanmar is home to the notorious "Golden Triangle," a major drug producing region that spans Myanmar, Laos, and Thailand) [15]. For certain occupations in Myanmar, such as miners in the north of the country, drug use is understood to be a problematic driver of morbidity, and programs target these groups with harm reduction and HIV interventions accordingly [9]. Yet fishermen in the south of the country fall almost entirely outside of these efforts, and national HIV surveillance data largely overlooks them and the Tanintharyi region in strategic documents [9]. Because of the retrospective, clinical nature of the data available for this analysis, an in-depth investigation of these factors was unavailable for this cohort and are worthy of future research. However our results make clear that HIV and harm reduction actors in Myanmar would do better to coordinate their activities to target fishermen with these programs.

Furthermore, risk factors such as IDU may be leading to increased proportions of HCV seroprevalence among fishermen. Rates seen in this analysis were higher than those found in other parts of Myanmar [16]. This is a serious issue. HCV therapies are not yet widely available in Myanmar, especially to vulnerable or indigent populations, and official guidance has only recently recommended using Direct Acting Anti-retrovirals (DAAs) rather than older, less expensive interferon based therapies that can interact with ART. Recent evidence has also suggested that people co-infected with HIV and HCV have a higher incidence of other illnesses, such as an almost two-fold risk of developing cancer [17]. The HIV/ $\mathrm{HCV}$ co-infection rates seen in these fishermen, as well as the inter-related patterns of fishing, injecting drugs, and transactional sex, warrant further in depth study to better target HIV and HCV prevention and screening efforts, as well as better treatment of both diseases.

\section{Limitations}

Some risk behavior related information may have been underestimated as 1) self-reported information about high risk sex and drug use is sensitive in the Myanmar cultural context, 2) in some cases, patients engaging in multiple high risk behaviors may not have had all their risk factors captured in clinic databases 3) risk information was asked about during initial clinic visits and may not account for changes in behavior during follow up. As with all operational research, some subtle inconsistencies in reporting due to staff transition may have occurred over a decade of data collection, particularly distinctions between types of fishermen.

\section{Conclusion}

In Southeast Asia, the HIV epidemic is not generalized, but resides within specific higher risk groups. This analysis shows that in Myanmar, outside of the traditional CSW, MSM, and IDU risk group categories, fishermen disproportionally inject drugs, are $\mathrm{HCV}$ co-infected, and engage in transactional sex. Since many of these men are migrating internationally, they are of note to HIV actors across the region. A better understanding how lengths of time at sea and destinations may affect their risk for disease transmission could better target this group. Introducing systematic HCV screening and harm reduction services for fishermen in Myanmar could be important to curbing both the HIV and HCV epidemics there.

\section{Abbreviations}

AIDS: Acquired Immunodeficiency Syndrome; ART: Anti-Retroviral Therapy; CD4: A glycoprotein in t-cells which are counted as an indicator of immune health; Cl: Confidence Interval; HCV: Hepatitus C Virus; HIV: Human Immunideficiency Virus; IQR: Inter-Quartile Range; MSF: Medecins Sans Frontieres; OR: Odds Ratio; TB: Tuberculosis

\section{Acknowledgements}

We thank the many MSF staff in Dawei, Yangon, and Geneva who provided support and input at various points during the study.

\section{Availability of data and materials}

The datasets generated and analyzed during the current study are not publicly available due to the sensitivities surrounding the MSF program in this particular humanitarian environment. However, they are available from the corresponding author on reasonable request.

\section{Funding}

The study was funded entirely with MSF project funds without external financing.

\section{Author's contributions}

All authors contributed to this study as part of regular duties as staff with Medecins Sans Frontieres-Switzerland in Myanmar and have read and approved the final manuscript. JO conceived of the study and participated in its design, coordination, statistical analysis, and drafted the manuscript. RN conducted the statistical analysis, drafted parts of the manuscript, and provided technical review, NTTK and EB participated in the design, and provided technical review of it. KPS participated in the design and data collection of the study and technical review of the manuscript, including drafting some manuscript content. RA provided input into the study design, data cleaning, and technical review of the manuscript. PEM, KPS coordinated the data collection and cleaning and provided technical insight during analysis and manuscript drafting. SC, MF, and WLS provided technical review of the manuscript throughout the study process (from conception through analysis and reporting). WLS also presented preliminary results at MSF's international research congress. IC oversaw the study, participated in its design and conception, and IC and SC provided final technical and editorial review of the manuscript as well as its final authorization. All authors read and approved the final manuscript. 


\section{Ethics approval and consent to participate}

This research fulfilled the exemption criteria set by the Médecins Sans Frontières Ethics Review Board for a posteriori analyses of routinely collected clinical data and thus did not require MSF ERB review. It was conducted with permission from Micaela Serafini, Medical Director, Operational Centre Geneva Médecins Sans Frontières. Additionally, formal Myanmar ERB approval was not sought for this retrospective analysis of routinely collected anonymized clinical and program data since national regulations currently do not require a formal ERB submission for reviews of program implementation, of which this research constitutes (more information can be found at http://www.ercdmrlm.org/welcome/index).

These data and findings have been shared formally at $\mathrm{MoH}$ public meetings and informally with counterparts from the Myanmar national AIDS and TB programs. All clinical care received by participants during the course of their treatment and reviewed in this analysis followed established medical ethical practice, and all research procedures conducted were in accordance with the Declaration of Helsinki.

\section{Consent for publication}

Not applicable.

\section{Competing interests}

All authors are staff with Medecins Sans Frontiers and declare no competing financial or non-financial relationships that could influence the outcome of this analysis.

\section{Publisher's Note}

Springer Nature remains neutral with regard to jurisdictional claims in published maps and institutional affiliations.

\section{Author details}

${ }^{1}$ MSF-Switzerland, Myanmar Project, \#101 Dhama Zedi Road, Kamayut Tsp, Yangon, Myanmar. ${ }^{2}$ MSF, Geneva, Switzerland. ${ }^{3}$ Medecins Sans Frontiers, 333 7th Avenue, 2nd Floor, New York, NY 10001, USA.

Received: 10 May 2018 Accepted: 26 November 2018

Published online: 14 December 2018

\section{References}

1. Kissling E, Allison E, Russell S, Bachmann M, Musgrave S, Heck S. Fisherfolk are among the groups most at-risk of HIV: cross-country analysis of prevalence and numbers infected. AIDS. 2005:19:1939-46.

2. Camlin C, Kwena Z, Dworkin S. Jaboya vs. Jakambi: status, negotiation, and HIV risks among female migrants in the "sex for fish" economy in Nyanza province, Kenya. AIDS Educ Prev. 2013;25(3).

3. Serwadda D, Sewankambo N, Carswell JW, Kirwa GB, Bayley A, Downing R, et al. Slim Disease: a new disease in Uganda and its association with HTLV-III Infection. Lancet. 1985:849-52.

4. Seeley J, Allison E. HIV/AIDS in fishing communities: challenges to delivering antiretroviral therapy to vulnerable groups. AIDS Care. 2005;17(6):688-97.

5. MKK C, El-Bassel N, PCG A, Gilbert L, Wu E, West BS, et al. Prevalence and correlates of HIV and hepatitis C virus infections and risk behaviors among Malaysian fishermen. PLoS One. 2015. https://doi.org/10.1371/journal.pone. 0118422.

6. Samnang P, Leng H, Kim A, Canchola A, Moss A, Mandel J, et al. HIV prevalence and risk factors among fishermen in Sihanouk Ville, Cambodia. Intl J STD AIDS. 2004:15:479-83.

7. West B, Choo M, El-Bassel N, Gilbert L, Wu E, Kamarulzaman A. Safe havens and rough waters: networks, place, and the navigation of risk among injection drug using Malaysian fishermen. Intl J Drug Policy. 2014;25(3).

8. Thawatwiboonpol EA, Ruffolo VP, Chinveschakitvanich V, Soskolne V, van Griensven GJ. HIV-1 prevalence, HIV-1 subtypes and risk factors among fishermen in the Gulf of Thailand and the Andaman Sea. AIDS. 2000:14(8):1027-34.

9. HIV Sentinel Sero-Surveillance Survey Report, National AIDS Programme, Department of Health, Ministry of Health, Myanmar. 2013.

10. Backmund M., Reimer J., Meyer K., Gerlach JT., Zachoval R. Hepatitis C virus infection and injection drug users: prevention, risk factors, and treatment. Clin Inf Disease 2005; 40(5) https://doi.org/10.1086/427475
11. UNHCR South-east Myanmar Information Management Unit. Tanintharyi Region Profile. (2014). http://data.unhcr.org/thailand/download.php?id=221. Accessed 11 May 2014

12. Entz, A; Prachuabmoh, V, Van Griensven, F., Soskine V. STD history, selftreatment, and healthcare behaviours among fishermen in the Gulf of Thailand and the Andaman Sea. Sex Trans Infections 2001; 76:436-440.

13. Ethics Review Committee. Department of Medical Research, Ministry of Health and Sports, Republic of the Union of Myanmar. http://www. ercdmrlm.org/. Accessed 11 May 2014.

14. Smolak A. A meta-analysis and systematic review of HIV risk behaviour among fishermen. AIDS Care. 2014;26(3):282-91.

15. United Nations Office on Drugs and Crime. Southeast Asia Opium Survey 2015: Lao PDR, Myanmar.http://www.unodc.org/documents/ southeastasiaandpacific/Publications/2015/Southeast_Asia_Opium_Survey_ 2015 web.pdf. Accessed online May 2014.

16. Zaw SK, Tun ST, Thida A, Aung TK, Maung W, Shwe M, et al. Prevalence of hepatitis $C$ and $B$ virus among patients infected with HIV: a cross-sectional analysis of a large HIV care programme in Myanmar. Trop Dr. 2014;43(3):113-5.

17. Meijide H, Pertega S, Rodriguez-Osorio I, Castro-Iglesias A, Balinas J, Rodriguez-Martinez G. Increased incidence of cancer observed in HIV/ hepatitis C coinfected patients versus HIV-monoinfected. AIDS. 2017;31(8):1099-107. https://doi.org/10.1097/QAD.0000000000001448.

\section{Ready to submit your research? Choose BMC and benefit from:}

- fast, convenient online submission

- thorough peer review by experienced researchers in your field

- rapid publication on acceptance

- support for research data, including large and complex data types

- gold Open Access which fosters wider collaboration and increased citations

- maximum visibility for your research: over $100 \mathrm{M}$ website views per year

At $\mathrm{BMC}$, research is always in progress.

Learn more biomedcentral.com/submissions 